Article

\title{
Synthesis of Ga-Doped ZnO Nanorods by Hydrothermal Method and Their Application to Ultraviolet Photodetector
}

\author{
Sheng-Joue Young ${ }^{1, *}$, Chia-Lin Chiou ${ }^{1}$, Yi-Hsing Liu ${ }^{2}$ and Liang-Wen $\mathrm{Ji}^{3}$ \\ 1 Department of Electronic Engineering, National Formosa University, Yunlin 632, Taiwan; \\ a8227059@yahoo.com.tw \\ 2 Institute of Microelectronics and Department of Electrical Engineering, Center for Micro/Nano Science and \\ Technology, Advanced Optoelectronic Technology Center, National Cheng Kung University, Tainan 701, \\ Taiwan; yhliu0870@gmail.com \\ 3 Institute of Electro-Optical and Materials Science, National Formosa University, Yunlin 632, Taiwan; \\ lwji@seed.net.tw \\ * Correspondence: shengjoueyoung@gmail.com; Tel.: +886-5-631-5560
}

Academic Editor: Chien-Hung Liu

Received: 6 January 2016; Accepted: 4 February 2016; Published: 16 February 2016

\begin{abstract}
In this study, high-density single crystalline Ga-doped $\mathrm{ZnO}$ (GZO) nanorods were grown on glass substrate by the hydrothermal method. The structural and optoelectronic properties of Ga-doped $\mathrm{ZnO}$ nanorods were studied. The microstructure of the GZO was studied by scanning electrical microscope (SEM). The structural characteristics of the GZO were measured by X-ray diffraction (XRD). It was found that the peaks related to the wurtzite structure $\mathrm{ZnO}$ (100), (002), and (101) diffraction peaks. The (002) peak indicates that the nanorods were preferentially oriented in the c-axis direction. The existence of Ga was examined by energy diffraction spectra (EDS), indicating the $\mathrm{Ga}$ atom entered into the $\mathrm{ZnO}$ lattice. The optical properties of the $\mathrm{GZO}$ were measured by photoluminescence spectra. It was found that all GZO nanorod arrays showed two different emissions, including UV (ultraviolet) and green emissions. GZO nanorod metal-semiconductor-metal (MSM) ultraviolet (UV) photodetectors (PD) were also fabricated. The photo-current and dark-current constant ratio of the fabricated PD was approximately 15.2 when biased at $1 \mathrm{~V}$.
\end{abstract}

Keywords: Ga doped ZnO nanorod; hydrothermal; photodetector

PACS: J0101

\section{Introduction}

$\mathrm{ZnO}$ has several favorable properties, such as a wide bandgap $(3.37 \mathrm{eV})$ and a large exciton-binding energy $(60 \mathrm{meV})$. Forms of $\mathrm{ZnO}$ with wurtzite structures have various morphologies such as nanowires, nanorods, nanotubes, and nanobelts [1-5]. $\mathrm{ZnO}$ nanorods are doped with various elements to alter their structural, electrical, and optical characteristics. Al, Ga, and In (group III) elements are used as dopants in the fabrication of n-type $\mathrm{ZnO}$ nanorods. $\mathrm{Ga}$ is an excellent dopant with high conductivity and low reactivity. As the covalent bond length of $\mathrm{Ga}-\mathrm{O}, 1.92 \AA$ is very close to that of $\mathrm{Zn}-\mathrm{O}$, which is $1.97 \AA$, and Ga-doped $\mathrm{ZnO}$ exhibits increased electron mobility and reduced electrical resistivity [6].

Various chemical, electrochemical, and physical deposition techniques have created structures of oriented $\mathrm{ZnO}$ nanorod arrays so far. For instance, metal-organic chemical vapor deposition [7], a vapor-liquid-solid epitaxial mechanism [8], pulsed laser deposition [9], spray pyrolysis [10], epitaxial electrodeposition [11], and radiofrequency magnetron sputtering [12] have been successful in creating highly oriented $\mathrm{ZnO}$ nanorods. The hydrothermal method is a simple low-temperature method for wet 
chemistry and thus has become a promising approach for the large-scale production of nanomaterials. Ya-Ping Hsieh et al. [13] synthesized a ZnO nanorod/Si nanotip with the pulsed laser deposition system. Huihu Wang et al. [14] synthesized Ga-doped $\mathrm{ZnO}$ nanorods with the hydrothermal method. Additionally, the method can directly obtain a product that has high crystallinity as well as excellent conductive properties without sintering. However, many of these demand reaction conditions such as high temperatures and low or high pressures, which go against the large-scale production of this material. Besides, there are also many advantages of $\mathrm{ZnO}$ nanorods grown on a glass substrate, such as low cost, greater transparency than the Si substrate, etc. Solution chemical processes greatly facilitate the fabrication of large-scale aligned $\mathrm{ZnO}$ nanorods with relatively low cost at remarkably low temperatures.

\section{Materials and Methods}

Initially, our glass substrate used RCA clean method (i.e., the RCA clean is a standard set of wafer cleaning steps) to clean residue, after that a 100-nm-thick $\mathrm{ZnO}$ seed layer was deposited on glass by radio frequency magnetron sputtering. Subsequently, a 50-nm-thick Au film was thermally evaporated through an interdigitated shadow mask onto the $\mathrm{ZnO}$ seed layer to form contact electrodes. The Ga-doped $\mathrm{ZnO}(\mathrm{GZO})$ nanorods were grown by hydrothermal method at $90^{\circ} \mathrm{C}$ for $6 \mathrm{~h}$. The synthesis solution was fabricated from zinc nitrate hexahydrate $\left(\mathrm{Zn}\left(\mathrm{NO}_{3}\right)_{2} 6 \mathrm{H}_{2} \mathrm{O}\right)$, hexamethylenetetramine and gallium nitrate hydrate $\left(\mathrm{Ga}\left(\mathrm{NO}_{3}\right)_{3} \cdot \mathrm{xH}_{2} \mathrm{O}\right.$, ) and mixed aqueous solution. Finally, the $\mathrm{GZO}$ nanorod substrate was washed with deionized water. Figure 1 show a schematic diagram of the fabricated the GZO nanorod photodetector.

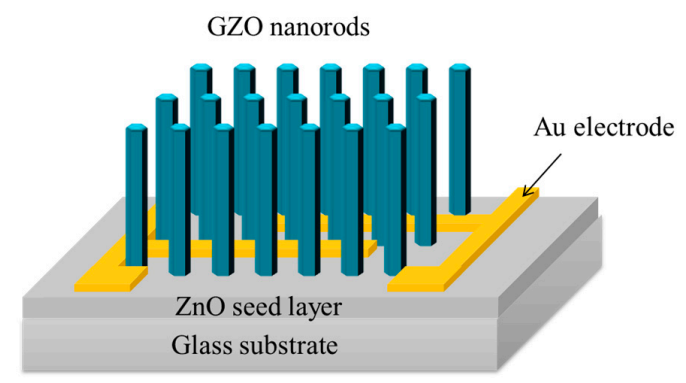

Figure 1. Schematic diagram of the fabricated GZO nanorod photodetector. The GZO nanorods are grown by hydrothermal method.

The surface morphologies and crystal quality of the synthesized materials were characterized using a high-resolution scanning electron microscope (Hitachi S-4800I, Hitachi High-Technologies corporation, Tokyo, Japan) and a high-resolution transmission electron microscope (HRTEM, Philips Tecnai F20 G2 FEG-TEM, Philips, Eindhoven, the Netherlands). X-ray diffractometer (XRD, Bruker D8 advance, Bruker, Germany) was used to characterize the crystallographic and structural properties of the grown GZO nanorods. The optical property of the samples were analyzed by a photoluminescence (PL) measurement system which was made at RT using a He-Cd laser $(325 \mathrm{~nm}, 5 \mathrm{~mW})$ as the excitation light source. A Keithley 2410 semiconductor parameter analyzer was then used to measure the I-V and photodetector characteristic of the fabricated device. The spectral responsivity of the photodetector was measured using a Jobin Yvon-Spex system with a $300 \mathrm{~W}$ xenon arc lamp light source (Perkin Elmer PE300BUV, PerkinElmer, Foster City, CA, USA) and a standard synchronous detection scheme measured at $300 \mathrm{~Hz}$.

\section{Results and Discussion}

Figure 2a,b show GZO nanorods have a well-aligned shape in the vertical direction as seen in the top-view and cross-section SEM image. Figure $2 \mathrm{a}$ indicates that the average diameters of the GZO were 
around 54 and $49 \mathrm{~nm}$, and Figure $2 \mathrm{~b}$ shows that average lengths were 1.96 and $1.28 \mu \mathrm{m}$, respectively. According to a previous report, the growth mechanism that explains this chemical reaction is as follows:

$$
\begin{gathered}
\left(\mathrm{CH}_{2}\right)_{6} \mathrm{~N}_{4}+6 \mathrm{H}_{2} \mathrm{O} \rightarrow 6 \mathrm{HCHO}+4 \mathrm{NH}_{3} \\
\mathrm{NH}_{3}+\mathrm{H}_{2} \mathrm{O} \leftrightarrow \mathrm{NH}_{4}^{+}+\mathrm{OH}^{-} \\
\mathrm{Zn}^{2+}+2 \mathrm{OH}^{-} \rightarrow \mathrm{Zn}(\mathrm{OH})_{2} \\
\mathrm{Zn}(\mathrm{OH})_{2} \stackrel{\Delta}{\rightarrow} \mathrm{ZnO}+\mathrm{H}_{2} \mathrm{O}
\end{gathered}
$$

During this synthesis, $\mathrm{Zn}\left(\mathrm{NO}_{3}\right)_{2}$ and HMTA serve as a $\mathrm{Zn}^{2+}$ ion source and a $\mathrm{pH}$ buffer, respectively. The latter keeps the $\mathrm{pH}$ values $\sim 7$. Hence, the formation of more surface defects at a lower $\mathrm{pH}$ is caused by the presence of more $\mathrm{H}^{+}$ions, which absorb more $\mathrm{OH}$ groups and $\mathrm{O}^{2-}$ ions [14-17].

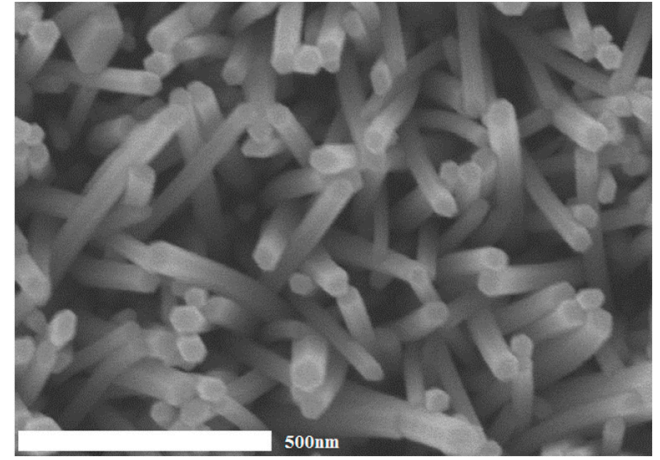

(a)

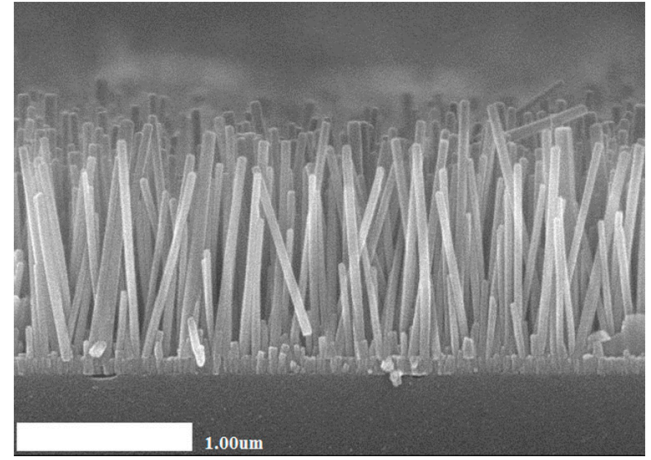

(b)

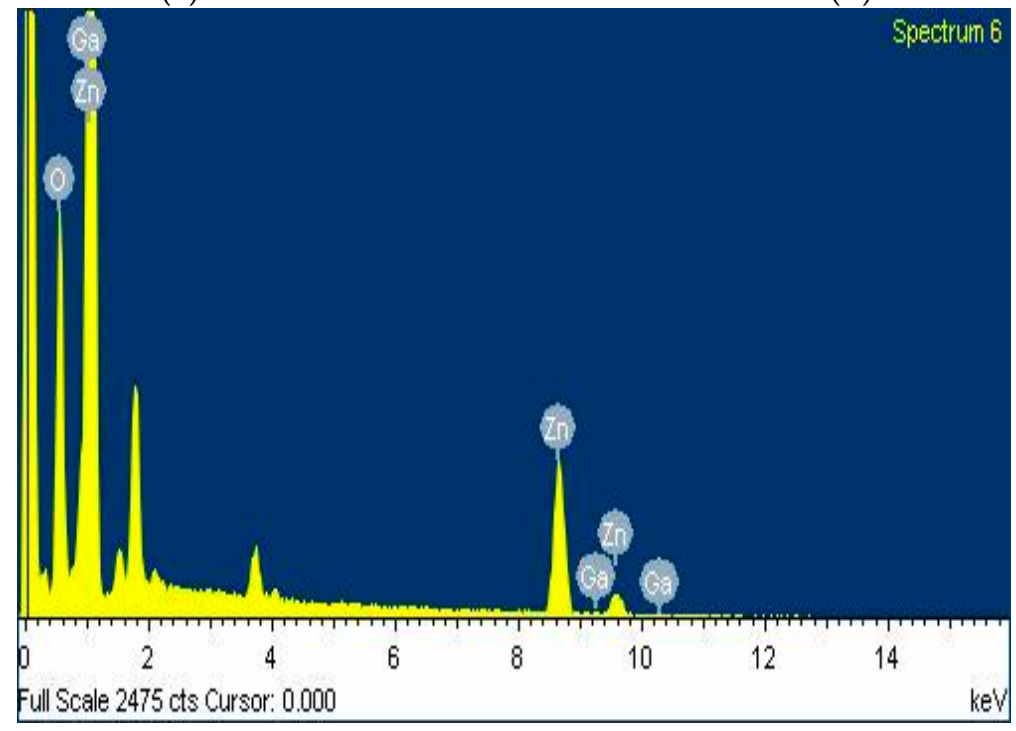

(c)

Figure 2. This figure shows GZO nanorods have a well-aligned shape in the vertical direction as seen in the top-view (a) and cross-section (b) SEM image. (c) shows that the existence of Ga was examined by energy diffraction spectra.

Figure 2c shows that the existence of Ga was examined by energy diffraction spectra (EDS), indicating that the $\mathrm{Ga}$ atom entered into the $\mathrm{ZnO}$ lattice. It is found that the GZO contains $40.11 \%$ zinc, $56.33 \%$ oxygen and $3.57 \%$ gallium as shown in Table 1 . The composition ratio of the nanorods is $\mathrm{Ga}_{0.008} \mathrm{Zn}_{0.992} \mathrm{O}$ which agrees well with the desired composition ratio. From the EDS, we see that no other element exists. 
Table 1. Shows the GZO nanorods contain zinc, oxygen and gallium, respectively.

\begin{tabular}{cccc}
\hline \multicolumn{4}{c}{ EDS } \\
\hline Element & O k & Zn L & Ga L \\
\hline Ga-doped ZnO & $56.33 \%$ & $40.11 \%$ & $3.57 \%$ \\
\hline
\end{tabular}

Figure 3 shows the structural characteristics of the GZO nanorods were measured by X-ray diffraction (XRD). It was found that the peaks related to the wurtzite structure $\mathrm{ZnO}$ (100), (002), and (101) diffraction peaks. The (002) peak indicates that the nanorods were preferentially oriented in the c-axis direction.

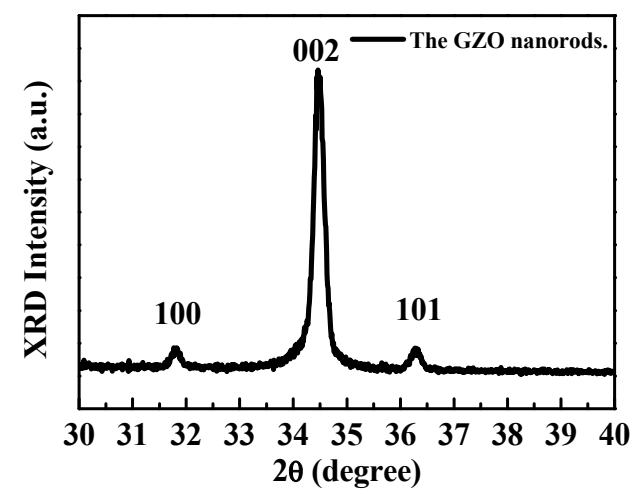

Figure 3. The XRD pattern of the GZO nanorods.

At room temperature, Figure 4 shows the optical properties of the GZO were measured by photoluminescence spectra. It was found that the GZO nanorod arrays exhibit two different emissions, including UV (ultraviolet) and green emissions. There is a reduction in the UV peak with Ga-doping because $\mathrm{Ga}$ atoms enter into the lattice sites, substituting for $\mathrm{Zn}$ atoms, causing serious lattice distortions and leading to decreased UV emission peaks. The green emission peak at $560 \mathrm{~nm}$ was attributed to the existence of oxygen vacancy and interstitial in our GZO nanorods.

According to previous works, the morphology of GZO nanorods will be converted into a nanosheet along with gallium-doped concentration increases. The crystal structure of GZO nanorods indicated a reduced crystallite quality of the $\mathrm{ZnO}$ nanorods (NRs) due to the incorporation of Ga atoms into the $\mathrm{ZnO}$ lattice network [17-19], and our PL spectra results are in agreement with previous reports suggesting that Ga doping improves the optical properties of ZnO NR arrays [14,20].

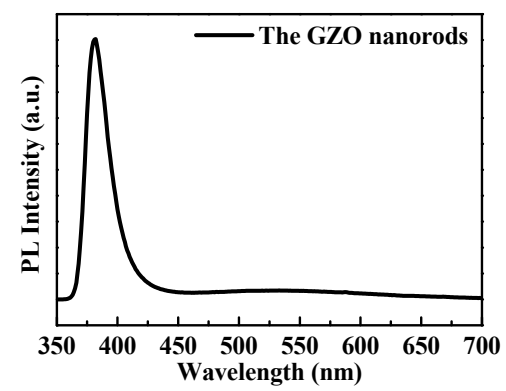

Figure 4. Room-temperature PL spectra of GZO nanorods.

Figure 5 shows the photocurrent rise and decay by turning the UV illumination at $365 \mathrm{~nm}$ on and off in the air. Before the UV illumination turned on, $\mathrm{O}_{2}$ molecules adsorbed on the surface of GZO nanorods and formed $\mathrm{O}_{2}{ }^{-}$by capturing the free electrons of the nanorods. Hence, the phenomenon 
decreases not only the carrier density but also the mobility of the remaining carriers by creating depletion layers near the surface [21,22]. When UV illumination is turned on, the photocurrent rapidly increases a huge number of electric-hold pairs. It can be attributed to the holes migrating to the surface to return $\mathrm{O}_{2}$ by desorbing the $\mathrm{O}_{2}{ }^{-}$under UV illumination. After UV illumination is removed, the dark currents decrease by recombining electron-hole pairs [14].

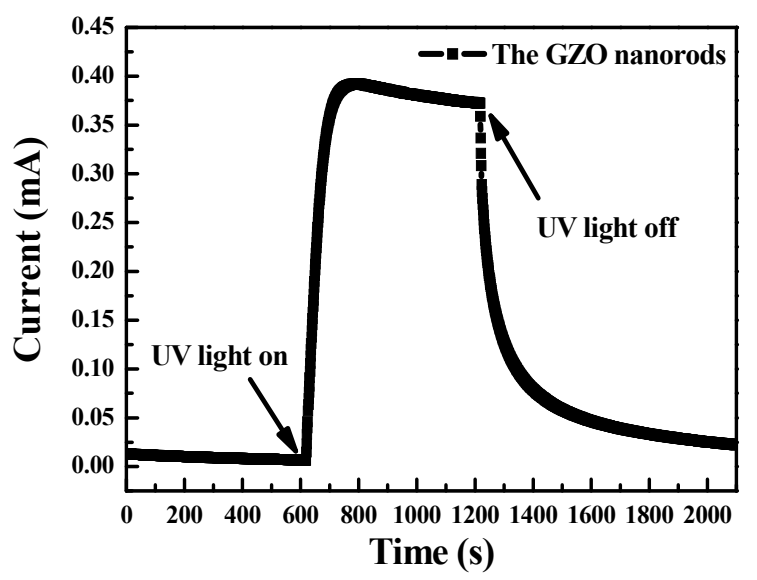

Figure 5. GZO nanorod current-time characteristics at UV illumination.

Under UV illumination at $365 \mathrm{~nm}$ in the air at an applied bias of $1 \mathrm{~V}$, the dark current and photocurrent of the GZO nanorod photodetector were $3.8 \times 10^{-4}$ and $2.5 \times 10^{-5} \mathrm{~A}$, respectively. The photocurrent-to-dark-current contrast ratio of the fabricated photodetector exceeded 15.2.

\section{Conclusions}

In summary, GZO nanorods were grown on a glass substrate by using a low-temperature hydrothermal method. The GZO nanorods exhibited wurtzite structures. The dynamic response of the GZO nanorod photodetector with Au electrodes had a photo current and dark current of $3.8 \times 10^{-4}$ and $2.5 \times 10^{-5} \mathrm{~A}$, respectively. The photocurrent-to-dark-current contrast ratio of the fabricated photodetector exceeded 15.2.

Acknowledgments: This work was supported by Ministry of Science and Technology under contract numbers MOST 104-2221-150-042 and MOST 103-2221-E-150-034. This work was also supported by National Science Council of Taiwan under contract numbers NSC 102-2221-E-150-046 and NSC 101-2221-E-150-043. The authors would like to thank the Common Laboratory for Micro/Nano Science and Technology, National Formosa University, for providing the partial equipment for measurement. They would also like to thank the Center for Micro/Nano Science and Technology, National Cheng Kung University, for the assistance in device characterization.

Author Contributions: Sheng-Joue Young conceived and designed the experiments; Chia-Lin Chiou and Yi-Hsing Liu performed the experiments; Liang-Wen Ji participated in data analysis. All authors read and approved the final manuscript.

Conflicts of Interest: The authors declare no conflict of interest.

\section{References}

1. Ji, L.W.; Peng, S.M.; Su, Y.K.; Young, S.J.; Wu, C.Z.; Cheng, W.B. Ultraviolet photodetectors based on selectively grown ZnO nanorod arrays. Appl. Phys. Lett. 2009, 94, 203106-1-203106-3. [CrossRef]

2. Ahsanulhaq, Q.; Umar, A.; Hahn, Y.B. Growth of aligned $\mathrm{ZnO}$ nanorods and nanopencils on $\mathrm{ZnO} / \mathrm{Si}$ in aqueous solution: Growth mechanism and structural and optical properties. Nanotechnology 2007, 18, 115603-1-115603-7. [CrossRef]

3. Kulkarni, A.J.; Zhou, M.; Ke, F.J. Orientation and size dependence of the elastic properties of zinc oxide nanobelts. Nanotechnology 2005, 16, 2749-2756. [CrossRef] 
4. Shen, X.P.; Yuan, A.H.; Hu, Y.M.; Jiang, Y.; Xu, Z.; Hu, Z. Fabrication, characterization and field emission properties of large-scale uniform ZnO nanotube arrays. Nanotechnology 2005, 16, 2039-2043. [CrossRef] [PubMed]

5. Li, C.; Fang, G.J.; Su, F.H.; Li, G.H.; Wu, X.G.; Zhao, X.Z. Synthesis and photoluminescence properties of vertically aligned $\mathrm{ZnO}$ nanorod-nanowall junction arrays on a $\mathrm{ZnO}$-coated silicon substrate. Nanotechnology 2006, 17, 3740-3744. [CrossRef]

6. Wan, Q.; Li, Q.H.; Chen, Y.J.; Wang, T.H.; He, X.L.; Li, J.P.; Lin, C.L. Fabrication and ethanol sensing characteristics of $\mathrm{ZnO}$ nanowire gas sensors. Appl. Phys. Lett. 2004, 84, 3654-3656. [CrossRef]

7. Liang, S.; Sheng, H.; Liu, Y.; Hio, Z.; Lu, Y.; Shen, H. ZnO Schottky ultraviolet photodetectors. J. Cyst. Growth 2001, 225, 110-113. [CrossRef]

8. Huang, M.; Wu, Y.; Feick, H.; Tran, N.; Weber, E.; Yang, P.D. Catalytic growth of zinc oxide nanowires by vapor transport. Adv. Mater. 2001, 13, 113-116. [CrossRef]

9. Choi, J.H.; Tabata, H.; Kawai, T. Initial preferred growth in zinc oxide thin films on Si and amorphous substrates by a pulsed laser deposition. J. Cyst. Growth 2001, 226, 493-500. [CrossRef]

10. Ambia, M.G.; Islam, M.N.; Hakim, M.O. The effects of deposition variables on the spray pyrolysis of ZnO thin film. J. Mater. Sci. 1994, 29, 6575-6580. [CrossRef]

11. Saito, N.; Haneda, H.; Sekiguchi, T.; Ohashi, N.; Sakaguchi, I.; Koumoto, K. Low-temperature fabrication of light-emitting zinc oxide micropatterns using self-assembled monolayers. Adv. Mater. 2002, 14, 418-420. [CrossRef]

12. Lee, J.Y.; Choi, Y.S.J.; Kim, H.; Park, M.O.; Im, S. Optimizing n-ZnO/p-Si heterojunctions for photodiode applications. Thin Solid Films 2002, 403-404, 550-557. [CrossRef]

13. Hsieh, Y.P.; Chen, H.Y.; Lin, M.Z.; Shiu, S.C.; Hofmann, M.; Chern, M.Y.; Jia, X.T.; Yang, Y.J.; Chang, H.J.; Huang, H.M.; et al. Electroluminescence from ZnO/Si-Nanotips light-emitting diodes. Nanoletters 2009, 9, 1839-1843. [CrossRef] [PubMed]

14. Wang, H.H.; Baek, S.; Song, J.J.; Lee, J.; Lim, S.W. Microstructural and optical characteristics of solution-grown Ga-doped ZnO nanorod arrays. Nanotechnology 2008, 19, 075607-1-075607-6. [CrossRef] [PubMed]

15. Hsiao, C.H.; Huang, C.S.; Young, S.J.; Chang, S.J.; Guo, J.J.; Liu, C.W.; Yang, T.Y. Field-emission and photoelectrical characteristics of Ga-ZnO nanorods photodetector. IEEE Trans. Electron Devices 2013, 60, 1905-1910. [CrossRef]

16. Ma, S.; Fang, G.J.; Li, C.; Sheng, S.; Fang, L.G.; Fu, Q.; Zhao, X.Z. Controllable synthesis of vertically aligned ZnO nanorod arrays in aqueous solution. J. Nanosc. Nanotechnol. 2006, 6, 2062-2066. [CrossRef]

17. Li, Q.C.; Kumar, V.; Li, Y.; Zhang, H.T.; Marks, T.J.; Chang, R.P.H. Fabrication of ZnO nanorods and nanotubes in aqueous solutions. Chem. Mater. 2005, 17, 1001-1006. [CrossRef]

18. Wang, B.Q.; Xia, C.H.; Iqbal, J.; Tang, N.J.; Sun, Z.R.; Lv, Y.; Wu, L. Influences of Co doping on the structural, optical and magnetic properties of $\mathrm{ZnO}$ nanorods synthesized by hydrothermal route. Solid State Sciences 2009, 11, 1419-1422. [CrossRef]

19. Hong, H.S.; Chung, G.S. Humidity sensing characteristics of Ga-doped zinc oxide film grown on a polycrystalline AlN thin film based on a surface acoustic wave. Sens. Actuators B: Chem. 2010, 150, 681-685. [CrossRef]

20. Phan, D.T.; Farag, A.A.M.; Yakuphanoglu, F.; Chung, G.S. Optical and photoluminescence properties of Ga doped $\mathrm{ZnO}$ nanostructures by sol-gel method. J. Electroceram. 2012, 29, 12-22. [CrossRef]

21. Ahn, C.H.; Han, W.S.; Kong, B.H.; Cho, H.K. Ga-doped ZnO nanorod arrays grown by thermal evaporation and their electrical behavior. Nanotechnology 2009, 20, 015601-1-015601-7. [CrossRef] [PubMed]

22. Li, Y.B.; Valle, F.D.; Simonnet, M.; Yamada, I.; Delaunay, J.J. Competitive surface effects of oxygen and water on UV photoresponse of ZnO nanowires. Appl. Phys. Lett. 2009, 94, 023110-1-023110-3. [CrossRef]

(C) 2016 by the authors; licensee MDPI, Basel, Switzerland. This article is an open access article distributed under the terms and conditions of the Creative Commons by Attribution (CC-BY) license (http://creativecommons.org/licenses/by/4.0/). 